DOE/ER/03130--54

DE9 $0 \quad 013327$

\title{
A Special function coprocessor for Level-2
}

\author{
D. Cutts, J.H. Hoftun, D. Nešić \\ C.R. Johnson, R.T. Zeller
}

\section{Introduction}

The idea of supplementing Level-2 filtering nodes with additional processing power has been alive within the D0 collaboration for some time now. ${ }^{1}$ The utility of additional processing power became increasingly recognized as the Level-2 filtering code matures. Here we will describe one scenario of augmenting Level-2 nodes with coprocessing power within the framework of the present D0 data acquisition system. Primary data reduction, consisting of repetitive but simple tasks, form the major part of the first order Level-2 filter, in terms of its time budget. Such computing tasks are well suited to the coprocessor environment. In what follows we will use the term Special Function Coprocessor (SFC) to denote this additional processor.

${ }^{1}$ D. Cutts, J.S. Hoftun, C.R. Johnson, R.T. Zeller, “A Microprocessor Farm Architecture for High Speed Data Acquisition and Analysis", presented at the IEEE 1988 Nuclear Science Symposium, Orlando (November 1988), Do Note \# 779;

D. Cutts, J.S. Hoftun, D. Nešić, C.R. Johnson, R.T. Zeller, "D0 Data Acquisition - High Speed Data Paths for D0", presented at the Eight Conference on Computing in High Energy Physics '90, Santa Fe (April 1990), D0 Note \# 972;

for an alternate proposal see D. Schamberger, J. Linnemann, "Calorimeter Hardware Processor Proposal", (May 1988)

\section{DISCLAIMER}

\footnotetext{
This report was prepared as an account of work sponsored by an agency of the United States Government. Neither the United States Government nor any agency thereof, nor any of their employees, makes any warranty, express or implied, or assumes any legal liability or responsibility for the accuracy, completeness, or usefulness of any information, apparatus, product, or process disclosed, or represents that its use would not infringe privately owned rights. Reference herein to any specific commercial product, process, or service by trade name, trademark, manufacturer, or otherwise does not necessarily constitute or imply its endorsement, recommendation, or favoring by the United States Government or any agency thereof. The views and opinions of authors expressed herein do not necessarily state or reflect those of the Uniter States ( Tovernment or any agency thereof.
} 


\section{DISCLAIMER}

This report was prepared as an account of work sponsored by an agency of the United States Government. Neither the United States Government nor any agency Thereof, nor any of their employees, makes any warranty, express or implied, or assumes any legal liability or responsibility for the accuracy, completeness, or usefulness of any information, apparatus, product, or process disclosed, or represents that its use would not infringe privately owned rights. Reference herein to any specific commercial product, process, or service by trade name, trademark, manufacturer, or otherwise does not necessarily constitute or imply its endorsement, recommendation, or favoring by the United States Government or any agency thereof. The views and opinions of authors expressed herein do not necessarily state or reflect those of the United States Government or any agency thereof. 


\section{DISCLAIMER}

Portions of this document may be illegible in electronic image products. Images are produced from the best available original document. 


\section{The special function coprocessor environment}

The Level-2 data acquisition system has been described elsewhere. ${ }^{2}$ Figure 1 presents a schematic of the data acquisition system. For our purpose of assisting the Level2 software filtering, the key location is the VME Multiport Memory (MPM). The MPM is central because the raw data arrives there from the digitizing crates and is not moved unless and until the event passes the Level-2 filter. A block diagram of the MPM is shown in Figure 2. A special function port on the MPM allows direct access to its data memory banks by devices communicating over a special bus. The size of the data memory banks is not fixed but is suited to the particular application. Digitized data from front end electronics will be transferred over the data cables to the MPM. It is a feature of the MPM that once the transfer is complete, memory access to the data memory banks is turned over to the VSB port. In that configuration the data memory bank appears as a transparent private memory to the Level-2 processor (currently a VAXstation $31 \mathrm{xx}$ ). It should be noted that if a SFC is attached to the special function port then the data memory banks and VAXstation private memory are transparent to the SFC. At the same time the SFC can become a "slave" to the VAXstation in the sense that processes in the SFC can be initiated under control of the Level-2 processor.

\section{General description of a special function coprocessor}

We intend to implement a SFC which will be operating in the 100 Mflops range To ensure maximum efficiency, the floating point format of the SFC will agree with the floating point format of the Level-2 processor. Typical processors which are available, use about $64 \mathrm{Kbyte}$ of the control memory for program storage. The Level2 processor has direct access to this control memory through the SFP and can invoke pre-programmed routines with a standard VAX Fortran function and/or subroutine call. It is this ease of communication and flexibility in programming the SFC that makes it a very nice tool for pre-filtering.

The programming of the SFC will be donc in a high level language and will be

\footnotetext{
${ }^{2}$ D. Cutts, J.S. Hoftun, R.T. Zeller, T. Trojak, R. Van Berg, C.R. Johnson, "Do Data Acquisition Design”, Proceedings of Fourth Conference on Real-Time Computer Applications in Nuclear and Particle Physics, IEEE Transactions in Nuclear Science, Vol. NS-32, (1985).;

D. Cutts, J.S. Hoftun, C.R. Johnson, R.T. Zeller, "The MircoVAX Based Data Acquisition System for D0", Proceedings of Fifth Conference on Real-Time Computer Applications in Nuclear and Particle Physics, IEEE Transactions on Nuclear Science, Vol. NS-34, (1987);

D. Cutts, J.S. Hoftun, C.R. Johnson, R.T. Zeller, "Data Acquisition Hardware for the D0 MicroVAX Farm", presented at the International Conference on the Impact of Digital Microprocessors on Particle Physics, Trieste, Italy (March 1988)

D. Cutts, J.S. Hoftun, C.R. Johnson, R.T. Zeller, "Data Acquisition at D0", presented at the Computing in High Energy Physics Conference, Oxford, England (1989), Computer Physics Communications Vol. 57 (1989)
} 
translated to the native SFC code with the appropriate compiler. Typical functions of the SFC would involve sequential or parallel (depending on the SFC) unpacking of digitized raw data, conversions to the floating point format with possible multiplications and additions and storing digested data into arrays which are convenient for further Level-2 filtering.

\section{Application to Calorimeter}

As an application of the SFC to the calorimeter filtering we have developed an algorithm for the calculation of energy (E) and transverse energy (Et). We plan to expand the algorithm to include the filling of a pointer array (PTCAEP) and we will examine the feasibility of calculating missing energy. Before describing the algorithm it is useful to recall one of the features of the data organization in the calorimeter banks. During data acquisition, the sequencer is scanning the VME crates to see if digitization is done and data is ready for transfer. Therefore the order of reading out the 12 ADC crates is, for all practical purposes, random-whichever is ready first will be read out first. Also, in a zero suppressed and pedestal subtracted mode, not all $12 \times 8 \times 4 \times 12=4608$ channels from a single crate are going to be digitized. All these features suggest that the unpacking of the address has to be based on the full address of every channel: 21 bits.

For the calorimeter application we estimate that 512 Kbyte per data cable is necessary on the MPM. Some fraction of that memory is occupied by the data transferred over two data cables from the calorimeter's VME crates. The rest is used for storing results of the SFC calculations and for tables needed in performing calculations. A possible division of these memory banks is given in Table 1. Raw data entry in the table corresponds to the space needed for storage of the data from the VME crates. In a typical event only $\approx 20 \%$ of the cells will have some energy deposited in them. Energy and $E_{t}$ entries will each take the same amount of space as raw data. In a typical event these three entries together will take $\approx 57 \mathrm{Kbyte}$. For the calculation of $E$ and $E_{t}$ there are two tables (arrays) which are large enning to deserve attention. One is the table of gain constants for each cell in the calorimeter and the other is the table of $\sin \theta$ values of each cell in the calorimeter.

D0 calorimeters have 55,296 instrumented channels of electronics but only 46,314 are connected to readout cells in the calorimeters. If gain constants are needed to an accuracy of $\approx 1.5 \%$ then there are less than 256 different ones and one can use a byte of storage per channel to point to the appropriate constant. Since the address of each channel is given by 17 bits, 128 Kbyte of storage space is needed for gain pointers. The space for $\sin \theta$ tables is based on the requirement that pointers to the $\sin \theta$ values for each channel should be at most one byte long. As a consequence every cell in the detector will have its $\sin \theta$ to precision better than $\approx 1.5 \%$ (See Appendix A). Exploiting the symmetry of $\mathrm{D} 0$, for a given vertex position one needs to know only 
CAD1

North Half

512 Kbyte

\begin{tabular}{|c|c|}
\hline Raw data & Raw data \\
94 Kbyte (max) & 94 Kbyte (max) \\
\hline Energy & Energy \\
94 Kbyte (max) & 94 Kbyte (max) \\
\hline$E_{t}$ & $E_{t}$ \\
94 Kbyte (max) & 94 Kbyte (max) \\
\hline Free space & Free space \\
139 Kbyte (min) & 139 Kbyte (min) \\
\hline $\sin \theta$ pointers \& constants & $\sin \theta$ pointers \& constants \\
27 Kbyte & 27 Kbyte \\
\hline Gain pointers and constants & Gain pointers and constants \\
64 Kbyte & 64 Kbyte \\
\hline
\end{tabular}

Table 1: Block diagram of data memory banks in MPM

2304 different pointers to $\sin \theta$ values. For NZ vertex positions, the number of pointers is $2304 \times \mathrm{NZ}$. We are assuming that vertex position will be passed from Level-0 as a 5 bit number so that $\mathrm{NZ}=32$, so the total space needed for $\sin \theta$ pointers is 73,728 bytes.

Please note that with all cells alive there are 278 Kbyte of free memory in the data memory banks in the MPM associated with calorimeter data. The PTCAEP array needs 81,60032 bit words of storage, $(75 \times 64 \times 17$, $)$ which is 326,400 bytes. If one routinely wants to fill the PTCAEP array every time a pre-filtering routine is called, then there is not enough memory to do so. But a typical event is expected to populate only $\approx 20 \%$ cells. If we decide to process through pre-filtering only events which have no more than $50 \%$ cells populated then the PTCAEP array can be accomodated. An undesirable alternative would be to fill the PTCAEP array in a separate call to SFC after the data from the MPM is moved elsewhere. .

An example of the code which could be run (after processor dependent compilation) in the SFC is included below. Here we calculate total energy and $E_{t}$ for each event. The code was tested on GEANT events: $50 \mathrm{GeV}$ electron (J version), $50 \mathrm{Gev}$ pion ( $\mathrm{J}$ version) and $120 \mathrm{Gev} t \overline{\mathrm{t}}$ (I version) events. The testing was done by comparing the CPU time it takes to run DOUSER package with and without CHECK_TABLES. The tests were done on D0HS09 (a VAXstation 3100 M38; its equivalent will be used as a Level-2 node in D0). For $50 \mathrm{Gev}$ electron events CHECK_TABLES takes 10.35 ms/event. For $120 \mathrm{Gev} t \overline{\mathrm{t}}$ events CHECK_TABLES takes $125 \mathrm{~ms} /$ event. The long 
time needed on the general purpose system for this simple, repeditive calculation highlights the enormous gain available through the use of a dedicated coprocessor. ${ }^{3}$

Here we enclose the source code of the subroutine CHECK_TABLES. Comments in the code should make it readable. It provides an example of our strategy for the code development for a SFC.

\footnotetext{
${ }^{3}$ Our SFC prototype will be based on a 100 MFLOP chip. For comparison, the nè Silicon Graphics 4D-300 system, with eight $33 \mathrm{MHz}$ RISC processors delivcring more than $200 \mathrm{MIPS}$, claims a performance of 30 MFLOPs.
} 


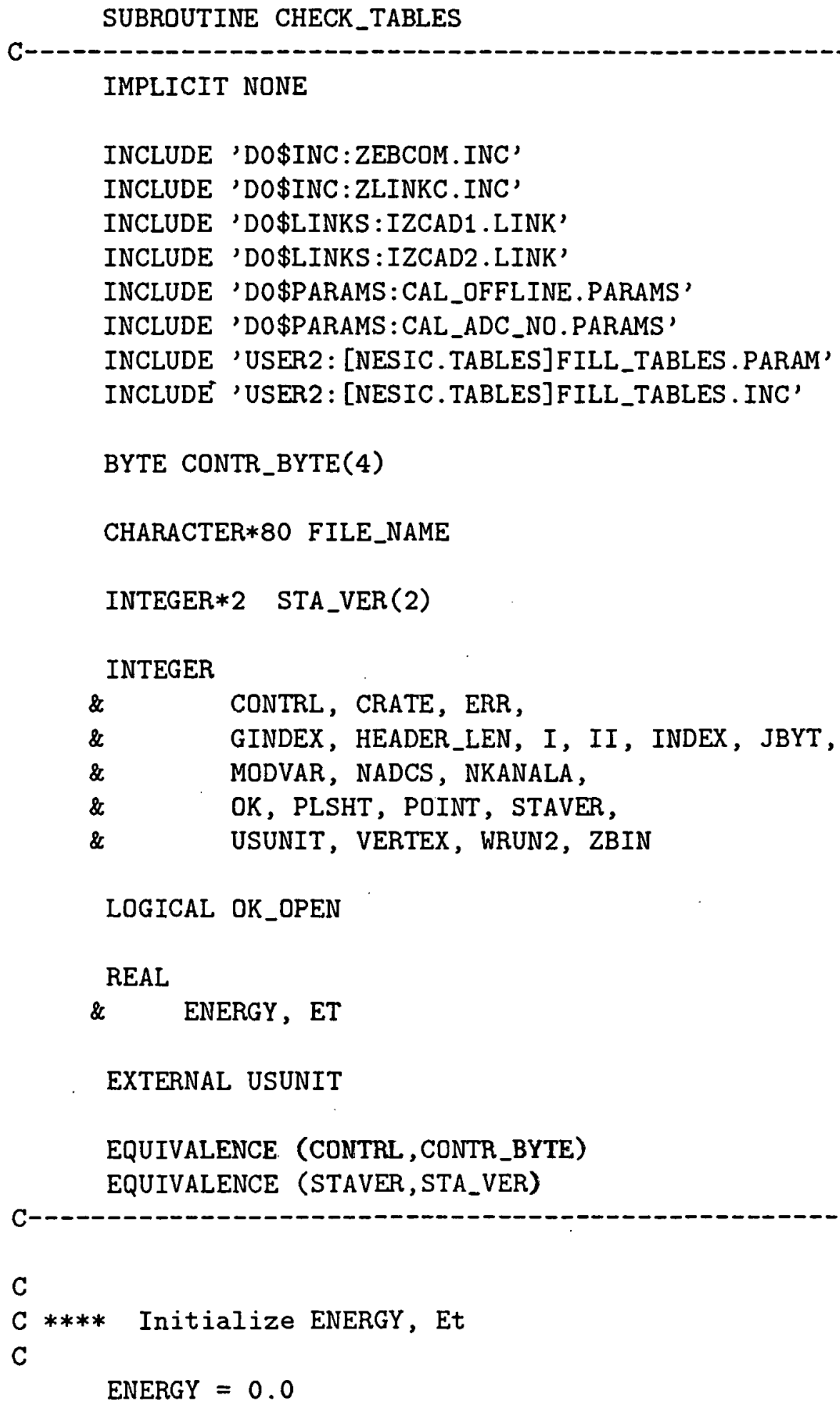




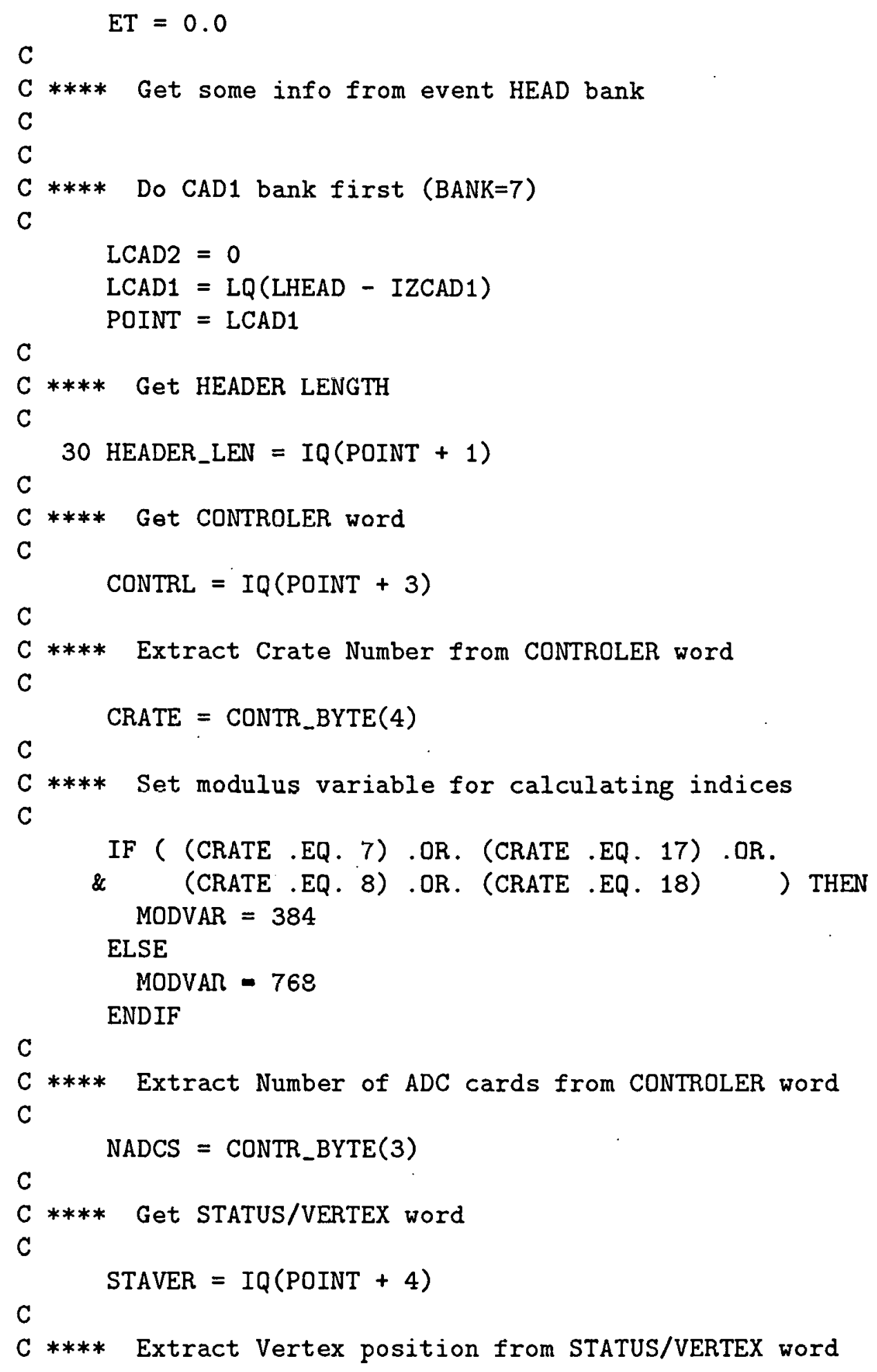


C

VERTEX $=$ STA_VER(1)

IF (VERTEX .NE. O) THEN

$\mathrm{ZBIN}=0$

ELSE

ZBIN = VERTEX

ENDIF

C

$\mathrm{C}$

C

POINT $=$ POINT + HEADER_LEN +2

DO $10 I=0$, NADCS

$\mathrm{C}$

C **** Get NUMBER OF DATA/ADDRESS WORDS for this card in this crate

$\mathrm{C}$

NKANALA $=$ IQ $($ POINT $)$

$\mathrm{C}$

C **** Loop over DATA/ADDRESS words

C

DO 20 II $=1$, NKANALA

POINT $=$ POINT +1

C

C **** Extract PULSE HIGHT and ADDRESS from

C $* * * *$ DATA/ADDRESS WORD $=$ IQ (POINT)

$\mathrm{C}$

C

DATA/ADDRESS word

$\mathrm{C}$

$\mathrm{C}$

$\mathrm{C}$

C

C

C

C

$1---1---1---1---1---1---1---1---1---1---1---1---1---1---1---1---1$

I ADC I BLS I ROTOW | DEPTH ISCL |NEG |

1 (Only 4 bits) I | | | | | | I IMI

1---1---1---1---1---1---1---1---1---1---1---1---1---1---1---1---1

$\begin{array}{llllllllllllllll}32 & 31 & 30 & 29 & 28 & 27 & 26 & 25 & 24 & 23 & 22 & 21 & 20 & 19 & 18 & 17\end{array}$

PLSHT $=\operatorname{JBYT}($ IQ $($ POINT $), 1,16)$

$\operatorname{INDEX}=\operatorname{JBYT}($ IQ $($ POINT $), 19,13)$

GINDEX = INDEX

CALL CBYT (CRATE_ID (CRATE) , 1, GINDEX , 14,3)

INDEX $=$ MOD (INDEX, MODVAR $)+$ CRATE_OFFSET (CRATE_ID (CRATE) $)$

\& $+(15+\mathrm{ZBIN}) * 2304$

C 


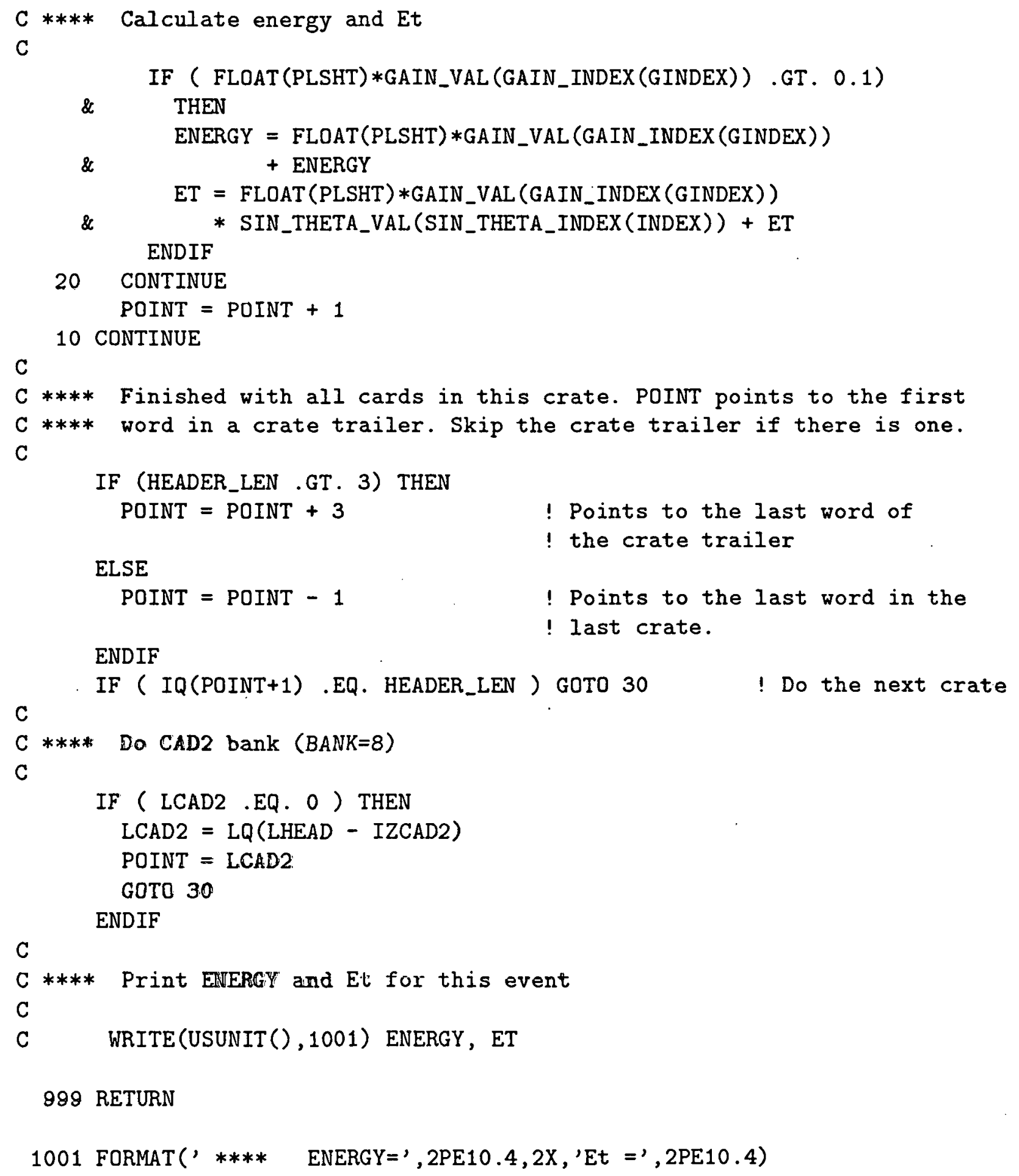


END

\section{Suggestions for code development}

In order to utilize the SFC efficiently several decisions have to be made for each application. One general question concerns the siting of the SFC: piggybacked on the MPM board (servicing its two data cable channels), or on a separate board which would have access to all data cable channels. Separate SFC's can operate simultaneously on their local data and can be tailored to specific applications, but a general SFC serving all channels is less expensive.

As part of the process of specifying the hardware design, one needs to know the memory needs for the application, which in turn depends on the algorithm one intends to implement, which in turn fixes code to a large extent. It is useful to keep all arrays one-dimensional even at the expense of the more complicated indexing and introduction of additional tables. To summarize in a few steps:

1. Start with the assumption that there is 256 Kbyte of memory available for the SFC. (This is the default memory size of each MPM channel.)

2. Identify what is it that needs to be calculated. A repeditive, highly compute intensive task makes the best target.

3. Develop algorithm. Keep in mind that you want to make best use of available memory. Also try to eliminate logical branches impeded in the computation (make best use of the MFLOP capacity).

4. Check if it is consistent with 1. If not go to 3 . and do it again.

5. When the algorithm is fixed, if it is consistent with 1., it gives everything you need to know to discuss the hardware design. If it is not consistent with 1 ., make a strong case that D0 should invest more in the memory and convince the financial control persons that if you do not get X Kbytes of memory we will never see the Wino.

\section{A : Table for $\sin \theta$}

Let us assume that there are only 8 bits available for pointing to the $\sin \theta$ of the cell. It means that there are only 256 different values of $\sin \theta$. Let us assume that $S T M A X$ and $S T M I N$ are the maximum and minimum values of $\sin \theta$ for cells in the D0 calorimeters and let us assume that there is an array $S I N(I), I=0, \ldots, 255$ such that $S I N(0)=S T M A X$ and $S I N(255)=S T M I N$. Let us denote by $E R R$ the ratio

$$
E R R=\frac{\operatorname{SIN}(I)-S I N(I+1)}{S I N(I)} .
$$


Then with STMIN $=0.0148$ and STMAX $=1.0$

$$
E R R=1-\left(\frac{\text { STMIN }}{\text { STMAX }}\right)^{\frac{1}{255}}=0.0164
$$




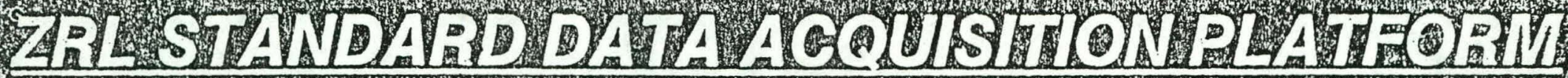

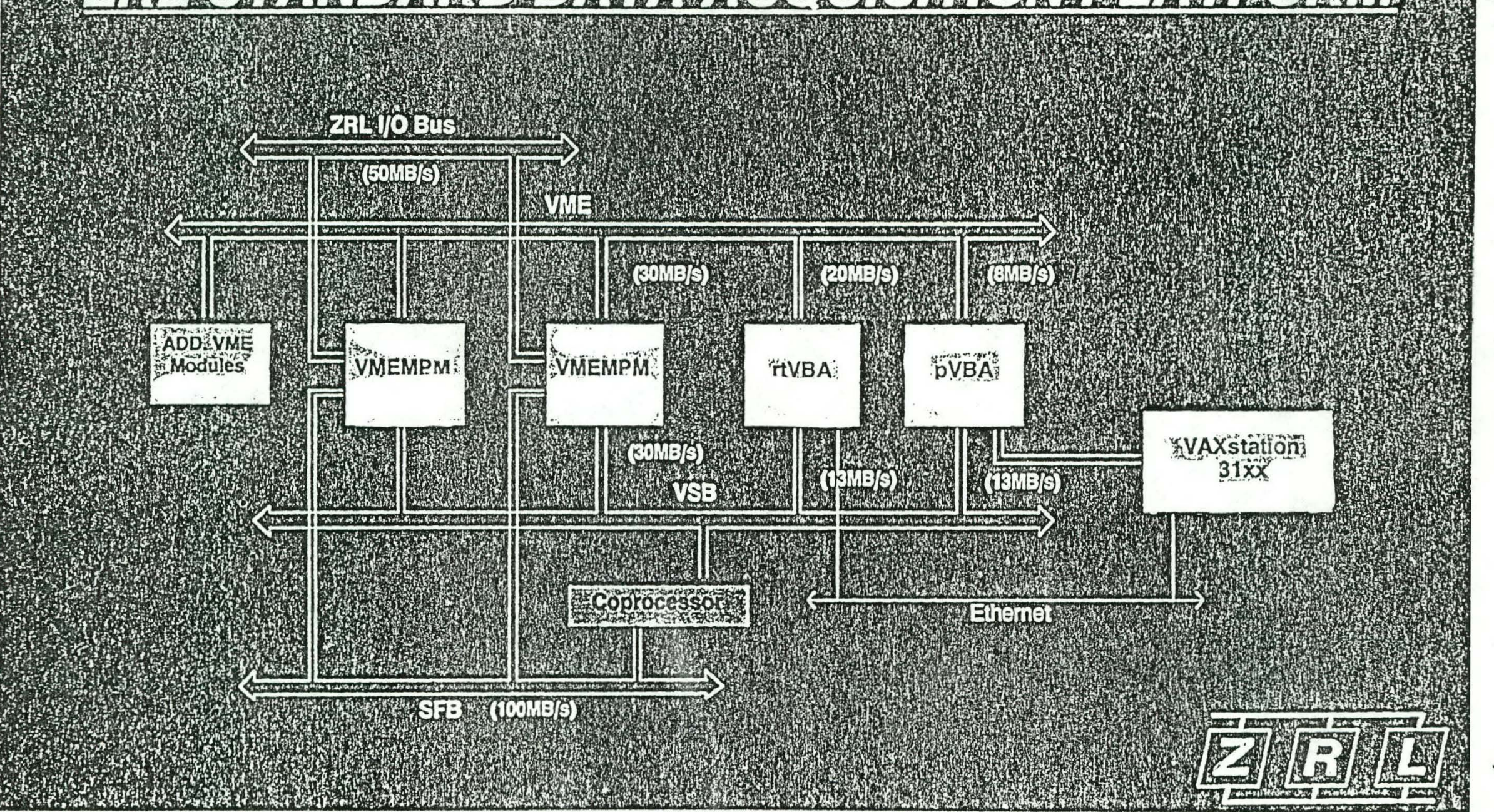




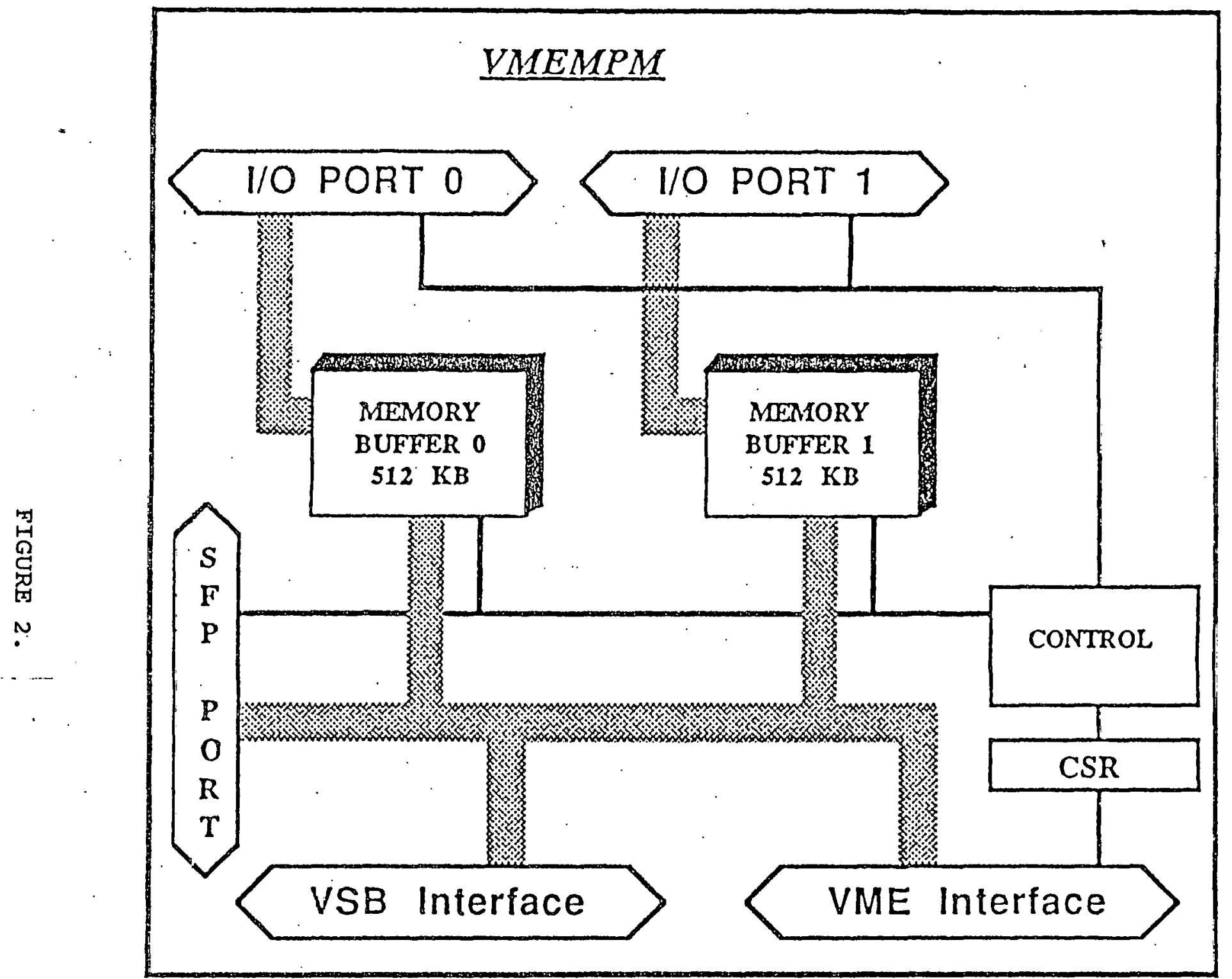

